\title{
PENGEMBANGAN PERANGKAT LUNAK KOMUNIKASI DATA SMS PADA SISTEM MONITORING LEVEL GAUGE
}

\author{
Djiwo Harsono $^{1}$, Adi Abimanyu ${ }^{2}$, Aryoko Wibowo ${ }^{1}$ \\ 1) STTN, BATAN, Yogyakarta, Indonesia, \\ 2) PSTA, BATAN, Yogyakarta, Indonesia, \\ E-mail: djiwo@batan.go.id
}

\begin{abstract}
ABSTRAK
PENGEMBANGAN PERANGKAT LUNAK KOMUNIKASI DATA SMS PADA SISTEM MONITORING LEVEL GAUGE. Monitoring level gauge minyak dalam tangki penampung minyak dari jarak jauh sangatlah penting, terutama jika areal perusahaan yang cukup luas sehingga operator dapat mengetahui ketinggiannya tanpa harus berjalan mendatangi tangki penampung tersebut. Pengukuran tersebut dapat dilakukan dengan berbagai cara, salah satunya yaitu level gauging radioisotop. Level gauging mempunyai banyak keunggulan dibanding dengan sensor elektonik, level gauging tidak dipengaruhi oleh ganguan-ganguan dari luar. Tujuan penelitian ini adalah untuk mengembangkan perangkat lunak komunikasi data SMS pada sistem monitoring level gauge dengan penampil LabVIEW. Ketinggian cairan dalam tangki penampung diukur dengan menggunakan perangkat modul level gauge yang kemudian data ini dikirimkan ke komputer operator yang berada di ruang kontrol melalui SMS. Modem Wavecom Fastrack USB digunakan untuk pengirim dan penerima data monitoring. Pada komputer terdapat program aplikasi yang dapat menampilkan ketinggian secara visual dalam bentuk angka, diagram batang, dan grafik yaitu LabVIEW. Delay time pada program LabVIEW diatur bertujuan untuk mendapatkan waktu komputasi yang optimum. Keseluruhan sistem dapat berjalan sesuai dengan yang diharapkan. Pada program mencari indeks didapat nilai delay time 1,5 ms dan pada program membaca SMS $20 \mathrm{~ms}$. Dari hasil pengujian dapat diketahui bahwa waktu komputasi optimum yang dibutuhkan perangkat lunak untuk mendapatkan data keseluruhan yaitu 992 ms.
\end{abstract}

Kata Kunci: SMS, modem, level gauge, LabVIEW

\begin{abstract}
DEVELOPMENT OF THE COMMUNICATION SMS DATA MONITORING SYSTEM LEVEL GAUGE SOFTWARE. Monitoring the oil high level in the tank of oil from a distance is very important, especially if the location of the company is wide enough so that the operator can determine the height without go to the tank. Where the measurements can be done in various ways, one of which is the level gauging using radioisotopes. Level gauging has many advantages compared with electronic sensors, level gauging is not affected by the disturbances from outside. The purpose of this research is to develop SMS communication software on the system level monitoring gauge with LabVIEW viewer. The height of the tank is measured by using the module level gauge and then the data are sent to the operator's computer in the control room via SMS. Wavecom Fastrack Modem USB is used for monitoring data sender and receiver. On the computer there is a program application that can visually display the height of the tank in the form of numbers, bar charts and graphs that are LabVIEW. Delay time is set in the LabVIEW program aims to obtain optimum computing time. The entire system can be run as expected. In looking for a program index values obtained delay time of $1.5 \mathrm{~ms}$ and at $20 \mathrm{~ms}$ SMS reading program. From the test results it can be seen that the optimum computing time required to obtain data software overall is $992 \mathrm{~ms}$.
\end{abstract}

Keywords: radiation monitoring, modem, SMS, LabVIEW

Djiwo Harsono dkk (1-8) 


\section{PENDAHULUAN}

Dalam sebuah industri perminyakan, pengukuran ketinggian tangki tertutup pada penyimpanan minyak sangatlah penting. Pengukuran tersebut dapat dilakukan dengan berbagai cara, seperti pengukuran metode level gauge. Keunggulan dari alat ini dibandingkan dengan alat ukur sensor elektris adalah bahwa level gauging tidak dipengaruhi oleh gangguan-gangguan yang bersifat fisis misalnya suhu, tekanan, dan kelembaban; sehingga akurasi, efisiensi, dan ketahanan dari alat ini relatif lebih baik daripada alat ukur yang menggunakan sensor elektris[1].

Proses monitoring tersebut perlu dilakukan secara kontinyu dan dikarenakan letak tangki yang jauh dari kantor, maka harus dipantau secara jarak jauh. Oleh karena itu dilakukan pengembangan dengan cara menambah sebuah modem agar dapat dipantau secara jarak jauh dan mempermudah operator dalam memantau ketinggian level.

Tujuan penelitian ini yaitu mengembangkan perangkat lunak komunikasi data SMS pada sistem monitoring level gauge dengan waktu komputasi yang optimum dan hasil dari pembacaan data dapat ditampilkan dengan software LabVIEW.

\section{Teori}

Untuk mendukung perancangan dan pembuatan software ini diperlukan pengetahuan tentang radiasi gamma, level gauging, modem Wavecom, Universal Serial Bus (USB), SMS, AT-Command, dan Software Labview.

\section{Radiasi}

Radiasi gamma mempunyai daya tembus sangat besar dan tidak dapat dihentikan sepenuhnya. Setiap pancaran radiasi yang mengenai suatu bahan akan berinteraksi dengan bahan yang dilewatinya. Perbandingan intensitas pancaran yang lewat dan intensitas yang diteruskan, tergantung pada tebal bahan, jenis bahan dan energi radiasi[2]. Besarnya intensitas dapat dinyatakan pada Persamaan (1)

$$
I_{t}=I_{o} e^{-\mu x}
$$

Dengan $I_{t}$ adalah Intensitas paparan radiasi yang diteruskan $(\mathrm{mR} / \mathrm{jam}) . I_{o}$ adalah Intensitas paparan radiasi yang datang $(\mathrm{mR} / \mathrm{jam}) . \mu$ adalah koefisien serap linier bahan pada energi tertentu $\left(\mathrm{mm}^{-1}\right)$ dan $\mathrm{x}$ adalah tebal bahan (mm).

\section{Level Gauging}

Level Gauging merupakan salah satu aplikasi iptek nuklir di bidang industri. Level Gauging digunakan untuk mengetahui batas permukaan dan ketinggian level suatu zat di dalam tangki yang tertutup. Keuntungan dari alat ini dibandingkan dengan alat ukur sensor elektris adalah bahwa level gauging tidak dipengaruhi oleh gangguan-gangguan yang bersifat fisis misalnya suhu, tekanan, dan kelembaban; sehingga akurasi, efisiensi dan ketahanan dari alat ini relatif lebih baik daripada alat ukur yang menggunakan sensor elektris [1]

Sistem level gauging dinamis adalah suatu sistem yang digunakan untuk mengetahui level ketinggian zat dengan konstruksi sumber radiasi dan detektor dalam keadaan bergerak (dinamis). Pergerakan naik/turun sumber radiasi dan detektor dilakukan oleh penggerak mekanik. Konstruksi sistem level gauging dinamis [3] ditunjukkan pada Gambar 1.

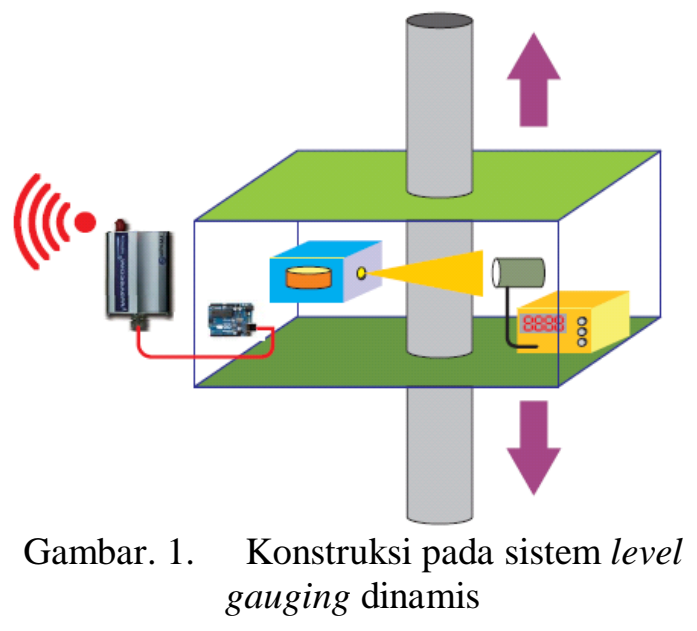

\section{Modem Wavecom Fastrack}

Modem adalah singkatan dari
Modulator-Demodulator yaitu proses
penerjemah dari digital ke analog sehingga
bisa ditransmisikan. Demodulate adalah
sebaliknya, proses menerjemahkan dari analog
ke digital. Modulator merupakan bagian yang
mengubah sinyal informasi ke dalam sinyal
pembawa (carrier) dan siap untuk dikirim,
sedangkan Demodulator adalah bagian yang
memisahkan sinyal informasi (yang berisi data
atau pesan) dari sinyal pembawa (carrier)


yang diterima sehingga informasi tersebut dapat diterima dengan baik[4]

Keuntungan menggunakan modem Wavecom Fastrack daripada Modem lain atau HP[5]:

1. Support AT-Command, bisa cek sisa pulsa, cek point, cek pemakaian terakhir dll

2. Tidak semua Modem GSM atau HP support AT-Command

3. Tidak memakai baterai sehingga lebih praktis.

\section{USB}

Komunikasi pada USB dilakukan secara serial. Serial lebih dipilih dibanding dengan paralel karena lebih mudah diterapkan dalam konfigurasi dinamik. Konfigurasi dinamik adalah suatu sistem masukan/keluaran dapat dikonfigurasi ulang dengan memasang atau melepas kabel ketika PC bekerja. Pada konfigurasi dinamik tidak diperlukan booting ulang[6].

\section{SMS}

SMS (Short Message Service) adalah sebuah layanan yang banyak diaplikasikan pada sistem komunikasi tanpa kabel (wireless), yang memungkinkan kita untuk melakukan pengiriman pesan dalam bentuk alphanumeric antara terminal pelanggan dengan sistem eksternal seperti e-mail, paging, voice mail, dan lain-lain[7]. Gambar 2 merupakan mekanisme cara kerja SMS.

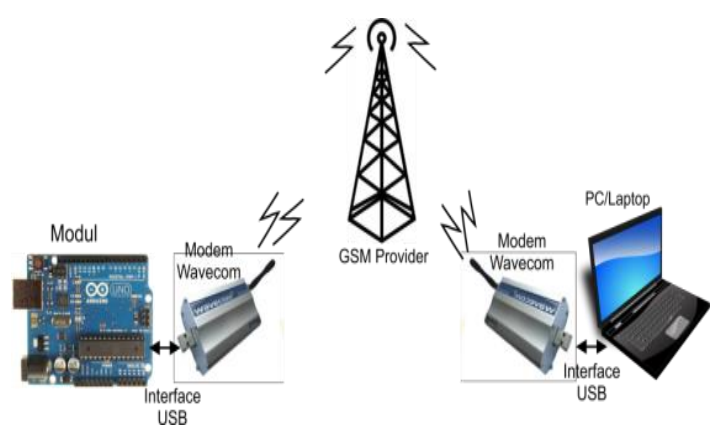

Gambar. 2. Skema cara kerja SMS

\section{AT-Command}

AT Command merupakan perintah standar yang dapat diterima oleh modem. AT Command dapat dipakai untuk memerintahkan modem mengirim dan menerima pesan SMS[8]. Beberapa AT Command yang penting untuk $S M S$ yaitu[9]:
1. $\mathrm{AT}+\mathrm{CMGF}=1$ : untuk mengatur mode teks.

2. AT+CMGS : untuk mengirim SMS. Dengan format $A T+C M G S=$ "No Tujuan" <enter $>$ Isi Pesan $\langle c t r l+z\rangle$

3. AT+CNMI $=1,1,0,0,0$ untuk mengatur agar modem mengirim notifikasi ke komputer saat diterima. Saat pesan diterima, maka komputer akan menerima pesan: +CMTI: "SM",9. "9" merupakan indeks SMS, yang artinya pesan tersimpan pada memori nomer 9 .

4. AT+CMGR : untuk membaca SMS. Dengan format $\mathrm{AT}+\mathrm{CMGR}=\mathrm{X}$ dengan $\mathrm{X}$ adalah indeks pesan.

\section{Software LabVIEW}

LabVIEW adalah sebuah software pemograman yang diproduksi oleh National Instruments. Seperti bahasa pemograman lainnya yaitu $C++$, matlab atau visual basic, LabVIEW juga mempunyai fungsi dan peranan yang sama, perbedaannya adalah LabVIEW menggunakan bahasa pemrograman berbasis grafis atau blok diagram sedangkan bahasa pemrograman lainnya menggunakan text. Program LabVIEW dikenal dengan sebutan VI atau virtual instruments karena penampilan dan operasinya dapat meniru sebuah instrument. Pada LabVIEW, user pertama-tama membuat user interface atau front panel dengan menggunakan kontrol dan indikator. Kontrol adalah peralatan input seperti knobs, push buttons, dials dan lainnya sedangkan yang dimaksud dengan indikator adalah perangkat output seperti graphs, LEDs dan peralatan display lainnya. Setelah menyusun user interface, kemudian menyusun blok diagram yang berisi kode-kode VIs untuk kontrol front panel[10].

\section{METODE}

Percobaan ini dibuat dengan cara perancangan sebagai berikut: Blok diagram sistem yang dibuat ditunjukkan pada Gambar 3. PC/Laptop berfungsi untuk menginteruksikan modul level gauge dan sebagai tampilan HMI. Modem berfungsi untuk menerima dan mengirim data hasil monitoring. 

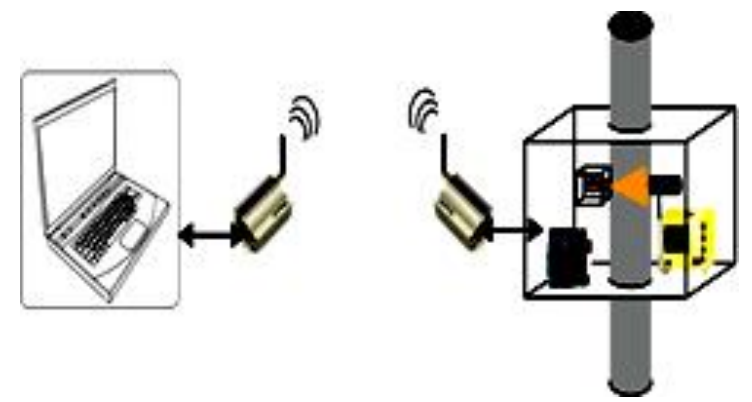

Gambar. 3. Blok Diagram sistem monitoring ketinggian

\section{Perancangan Perangkat Lunak}

Diagram alir perancangan perangkat lunak ditunjukkan pada Gambar 4.

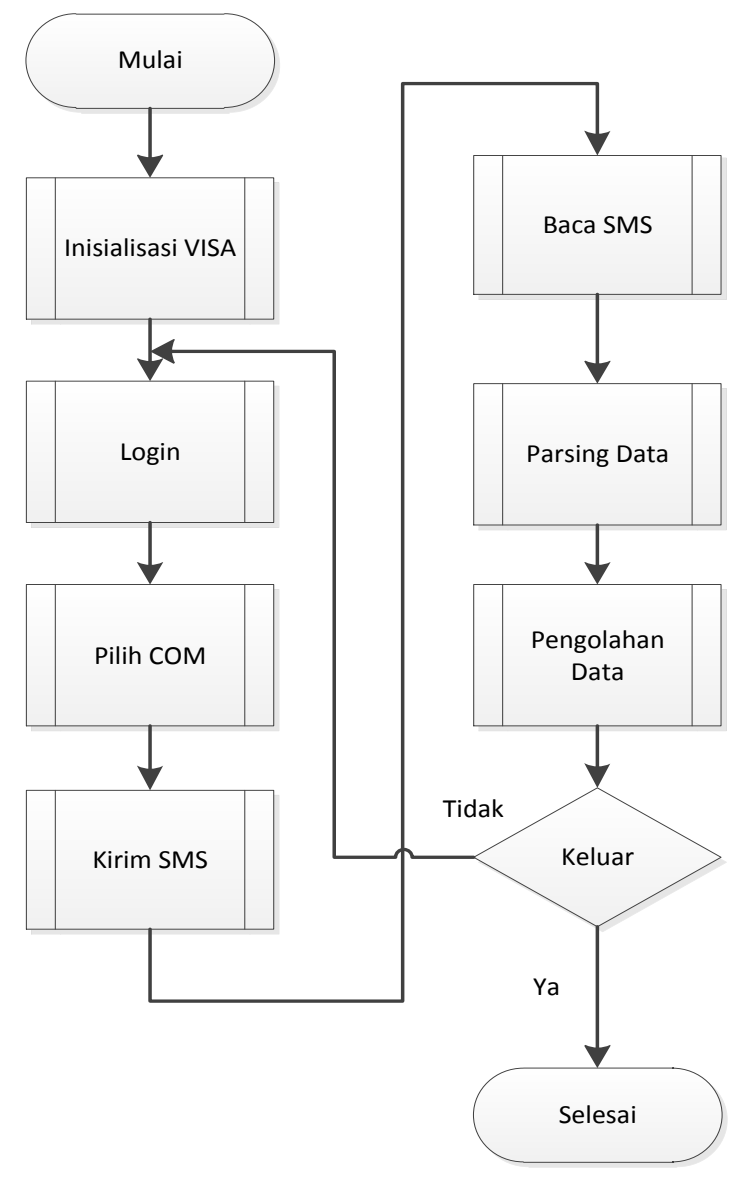

Gambar. 4. Diagram alir perancangan perangkat lunak

Inisialisasi merupakan sebuah proses awal, inisialisasi Port COM ini akan keluar ketika modem terhubung dengan modem. Diagram alir inisialisasi visa serial, modem harus terhubung terlebih dahulu agar visa serial dapat teridentifikasi oleh PC/Laptop.

Proses $\log$ in merupakan langkah awal sebelum memulai untuk melakukan kegiatan pemantauan melalui LabVIEW. Dalam proses $\log$ in, diminta untuk mengisikan nama pengguna dan kata sandi terlebih dahulu. Ketika nama pengguna atau kata sandi yang dimasukkan tidak sesuai, maka tidak dapat melanjutkan proses selanjutnya. Alasan penggunaan kata sandi untuk masalah kemanaan.

Proses pilih COM berfungsi untuk memilih port COM yang terhubung dengan peralatan dari luar, dalam penelitian ini yaitu modem. Gambar 3. 8 merupakan diagram alir proses pilih COM. Untuk menggunakan komunikasi serial, ada beberapa parameter yang harus diatur seperti Baudrate, flow control, parity, data bits, dan stop bits. Pada penelitian ini konfigurasi visa serial diatur; Baudrate (115200), flow control (none), parity(none), data bits (8), dan stop bits (1,0).

Proses kirim SMS digunakan untuk mengirim pesan interuksi melalui modem Wavecom pada PC/Laptop ke modem Wavecom yang terhubung pada modul level gauge. Perintah kirim SMS dalam bentuk string dengan format $A T+C M G S=$ "No Tujuan" <enter $>$ Isi Pesan $\langle c t r l+z>$. Dalam bentuk blok diagram Labview, $\langle c t r l+z\rangle$ pada program LabVIEW diganti sandi ASCII

Proses baca SMS langkah pertama yaitu konfigurasi modem diatur dengan menggunakan software hyperteminal dengan format $\mathrm{AT}+\mathrm{CNMI}=1,1,0,0,0$ agar modem mengirim notifikasi ke komputer saat data SMS diterima. Saat pesan diterima, maka komputer akan menerima pesan: +CMTI: "SM",X. "X" merupakan indeks SMS, yang artinya pesan tersimpan pada memori nomer $\mathrm{X}$ melalui pembacaan data serial pada register. . Program yang dibuat melakukan pembacaan sampai menemukan indeks "SM". Setelah mendapatkan "SM", data akan dibaca dengan mengirim perintah dalam bentuk string $\mathrm{AT}+\mathrm{CMGR}=\mathrm{X}$, maka akan dibalas modem dengan informasi +CMGR : "Status SMS","nomor pengirim","tanggal, jam" $\langle\mathrm{CR}\rangle\langle\mathrm{LF}\rangle$ isi pesan. Berdasarkan informasi balasan dari modem dapat diketahui nomer pengirim SMS, tanggal, jam dan isi SMS[11]. Pada proses baca SMS terdapat filter nomer. Selain nomer yang ditentukan data yang masuk tidak akan diolah oleh program.

Proses Parsing berfungsi untuk memisahkan data sehingga didapatkan isi SMS berformat $=\mathrm{X} \#$ dengan $\mathrm{X}$ merupakan data ketinggian yang ditampilkan dari hasil proses parsing. Bilamana tidak ada masukan data maka tidak ada parsing yang dilakukan. 
Parsing dilakukan dengan mencari karakter header dan footer untuk data yang masuk.Proses pengolahan data, data hasil proses parsing untuk kemudian diolah dalam bentuk penampil informasi data ketinggian tangki seperti; numeric indication, waveform chart, dan dari data nilai ketinggian diolah menjadi volume tangki dengan memasukkan data luas alas tangki. Dari data tersebut juga diolah dalam tabel string, yang berisi data nomor, tanggal, waktu, dan data volume dari pemantauan menggunakan level gauge.

\section{Perancangan Tampilan LabVIEW}

Gambar 5. merupakan rancang aliran state machine yang akan dibangun. Proses tersebut merupakan proses dari awal $\log$ in hingga keluar proses monitoring.

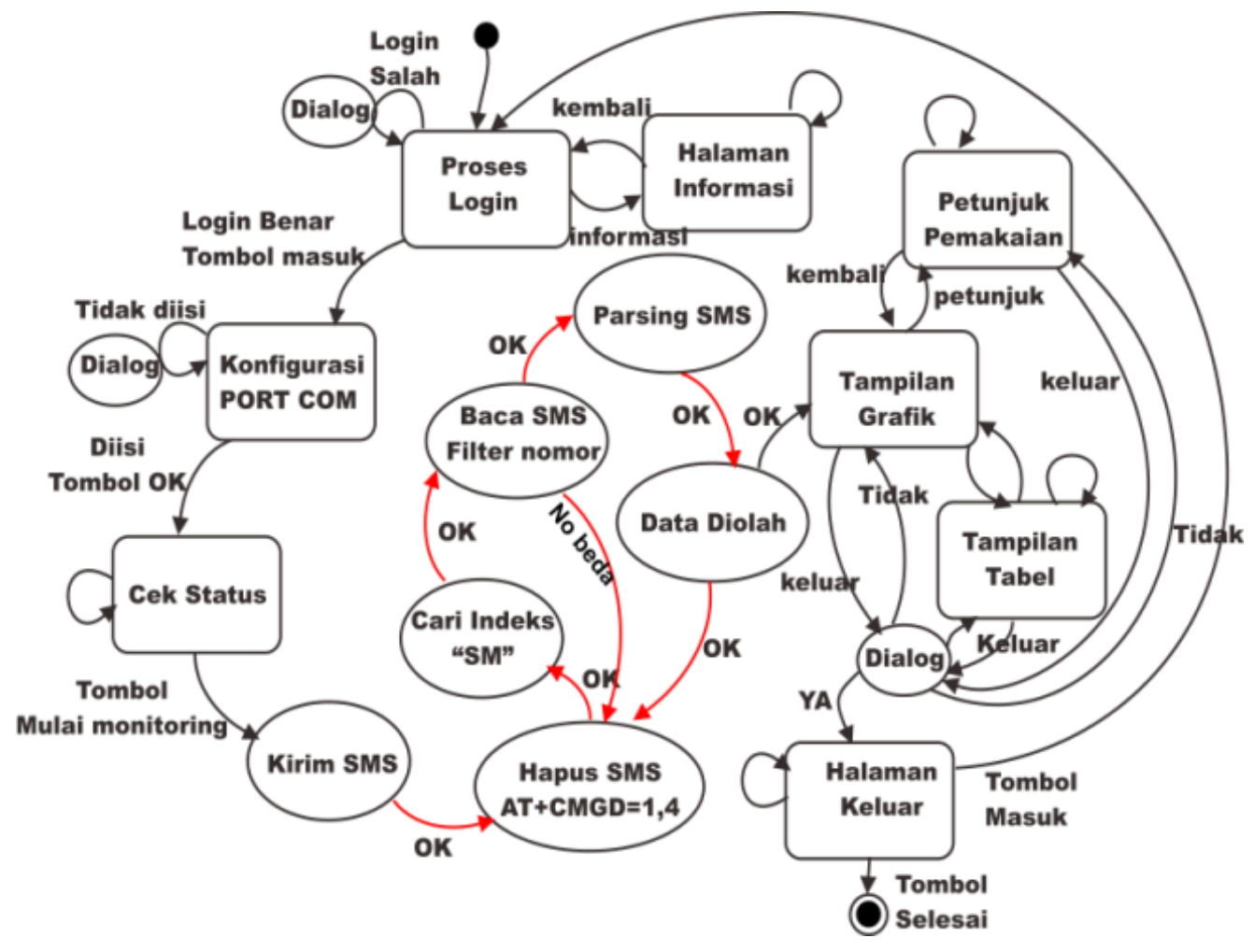

Gambar. 5. Aliran state machine LabVIEW

\section{HASIL DAN PEMBAHASAN}

\section{Hasil Pengujian Waktu Respon Modem}

Pengujian waktu respon modem bertujuan untuk mengetahui nilai waktu minimal yag dibutuhkan modem untuk merespon perintah AT Command

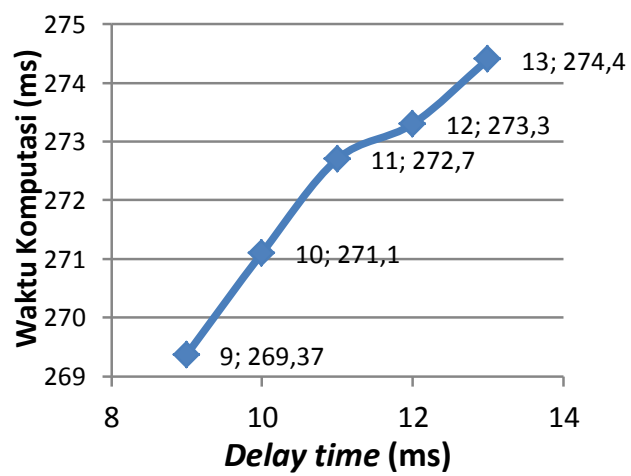

Gambar. 6. Hubungan delay time dengan waktu komputasi

Pengujian respon modem dilakukan dengan memvariasikan delay time dari $8 \mathrm{~ms}-$ $13 \mathrm{~ms}$ dengan interval $1 \mathrm{~ms}$, pada delay time 8 
ms terjadi error. Dari 30 kali pengambilan data terdapat 4 kali modem tidak memberi balasan OK. Secara keseluruhan pada delay time $9 \mathrm{~ms}$ - 13 ms, dari 30 kali pengujian mendapatkan respon OK. Didapatkan waktu komputasi untuk masing-masing variasi delay time tersebut; $9 \mathrm{~ms}(269,3 \mathrm{~ms}), 10 \mathrm{~ms}(271,1 \mathrm{~ms})$, $11 \mathrm{~ms}(272,7 \mathrm{~ms}), 12 \mathrm{~ms}(273,3 \mathrm{~ms})$ dan pada delay time $13 \mathrm{~ms}(274,4 \mathrm{~ms})$. Pada Gambar 6. adalah grafik hubungan waktu komputasi dan delay time. Semakin besar delay time maka semakin lama waktu komputasi yang diperlukan dalam memberi respon OK. Sehingga dapat disimpulkan, delay time minimum yang dibutuhkan modem untuk merespon OK pada pengembangan program ini sebesar 9 ms dengan waktu komputasi 269,37 ms.

\section{Pengujian Waktu Komputasi Mencari Indeks SMS "SM"}

Pengujian waktu komputasi mencari indeks SMS "SM" bertujuan untuk mengetahui nilai waktu minimal yang dibutuhkan program untuk mendapatkan indeks "SM".

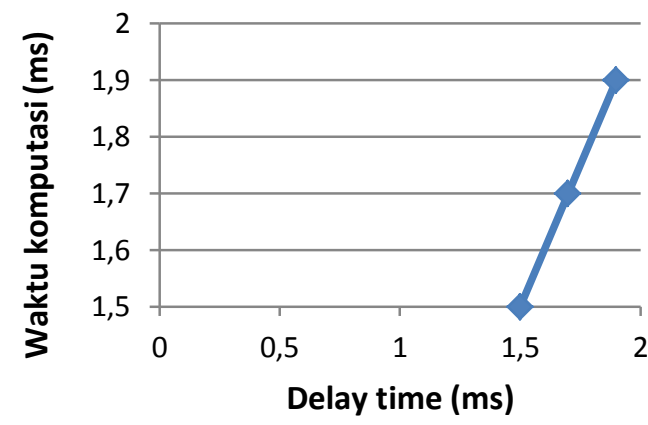

Gambar. 7. Hubungan Waktu komputasi dengan delay time pada program indeks SM

Delay time pada program ini sebanding dengan waktu komputasi. Nilai delay time agar dapat membaca indeks $S M$ secara lengkap sebesar 1,5 ms, ditunjukkan pada Gambar 7 .

\section{Pengujian Waktu Komputasi Membaca SMS}

Pengujian waktu komputasi membaca SMS bertujuan untuk mengetahui waktu komputasi program untuk membaca data hingga menampilkan pada bentuk grafik dan tabel pada LabVIEW.

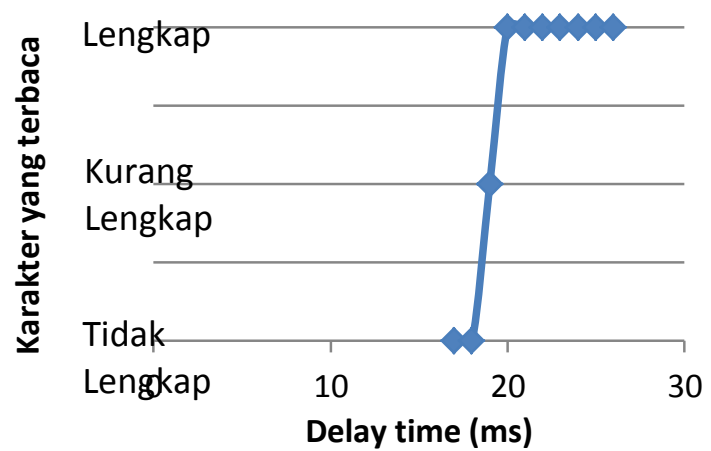

Gambar 8. Hubungan delay time baca SMS dengan karakter yang dibaca

Keterangan jumlah karakter;

-Tidak Lengkap : 0-68

-Kurang Lengkap : 69-231

-Lengkap : lebih dari 232

Format yang diterima pada program visa read

"AT+CMGR=(indeks SMS)

+CMGR: "REC UNREAD","(Nomor

handphone)",,"(tanggal),(waktu)"

$\langle\mathrm{CR}\rangle\langle\mathrm{LF}\rangle$

(isi pesan)

OK”

Pada Gambar 8. program dapat membaca data SMS secara keseluruhan pada delay time $20 \mathrm{~ms}$ seterusnya. Sehingga nilai delay time yang digunakan untuk membaca data SMS secara keseluruhan dalam program membaca SMS adalah $20 \mathrm{~ms}$.

\section{Pengujian Waktu Komputasi Membaca SMS}

Pengujian waktu komputasi program LabVIEW bertujuan untuk mengetahui berapa nilai waktu minimum yang dibutuhkan program untuk memproses data sampai program menampilkan data, sehingga program tersebut bekerja secara optimum. Pada pengujian ini didapat nilai rata-rata waktu komputasi sebesar $992 \mathrm{~ms}$.

\section{Pengujian Keseluruhan dan Tampilan Labview}

Hasil tampilan LabVIEW, Tampilan $\log$ in merupakan tampilan pertama sebelum melakukan proses pemantauan ditunjukkan pada Gambar 9. 


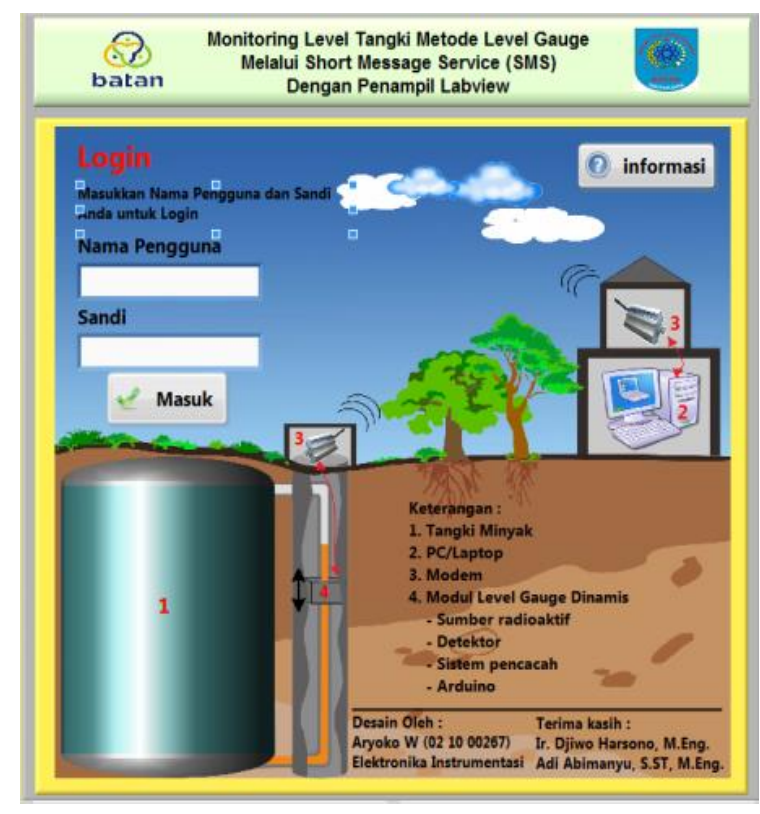

Gambar 9. Gambar halaman login

Hasil tampilan LabVIEW ketika melakukan proses monitoring ditunjukkan pada Gambar 10. Ketika modul level gauge masih mendeteksi adanya cairan di dalam tangki dengan volume 2826 liter, dan ketika modul level gauge tidak mendeteksi adanya cairan yaitu dengan indikator cacah yang diterima mengalami perubahan yang drastis pada Gambar 11. Volume yang terekam pada monitoring tersebut tetap sama sebesar 2826 liter. Pengujian ini membuktikan program telah berhasil dibuat untuk memberi informasi kepada operator bahwa daerah perbatasan level zat berada pada ketinggian $36 \mathrm{~m}$ dengan volume 2826 liter.

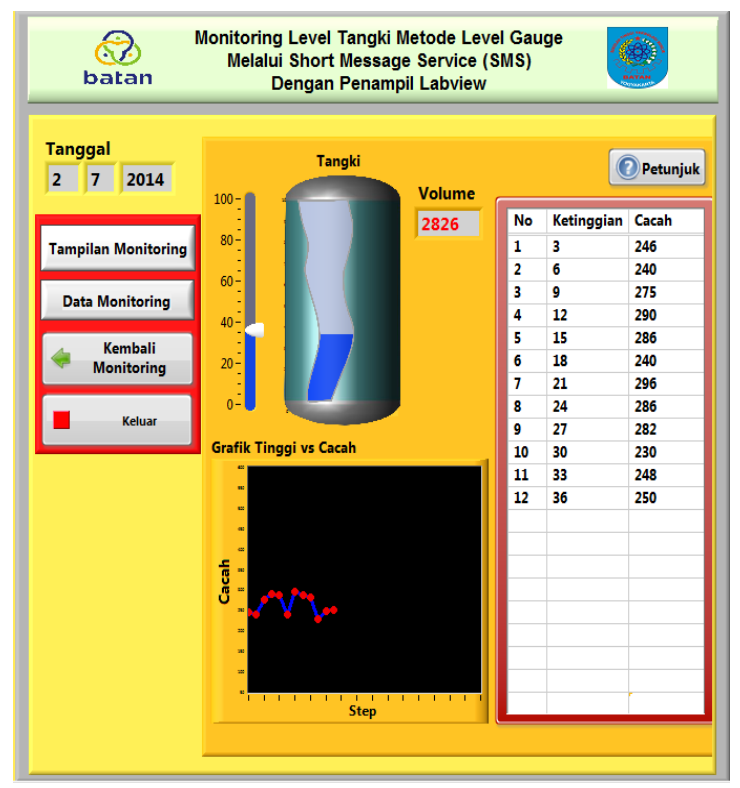

Gambar 10. Tampilan monitoring

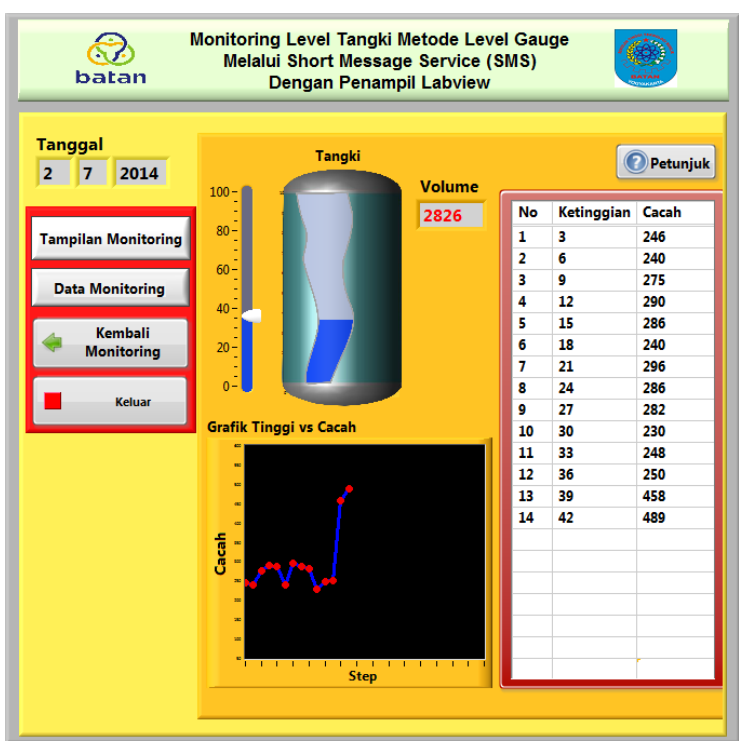

Gambar 11. Tampilan monitoring

\section{KESIMPULAN DAN SARAN}

Berdasarkan hasil dari proses pengujian dan pengamatan kinerja sistem secara keseluruhan serta mengacu pada tujuan dari tugas akhir pada pengembangan perangkat lunak yang dibuat pada penelitian ini, maka disimpulkan; Telah berhasil dibuat pengembangan perangkat lunak komunikasi data SMS pada sistem monitoring level gauge dengan penampil Labview. Delay time optimum yang dibutuhkan modem untuk menerima perintah AT-Command adalah $9 \mathrm{~ms}$ dengan waktu komputasi sebesar 269,73 ms. Delay time optimal yang dibutuhkan program untuk dapat membaca SMS secara utuh adalah 20 ms. Waktu komputasi keseluruhan yang dibutuhkan untuk dapat menampilkan data ke dalam LabVIEW sebesar 992 ms.

\section{Saran}

Beberapa saran yang dapat diberikan untuk memperbaiki dan mengembangkan penelitian ini di waktu mendatang antara lain:

1. Hasil report pada penelitian ini dapat dikembangkan berbasis database

2. Untuk berkomunikasi antara PC/Laptop dengan modul level gauge dapat dikembangkan dalam bentuk wireless. Karena keberhasilan menggunakan modem SMS pada system monitoring ini bergantung pada ada/tidak adanya SMS error dan penundaan pengiriman SMS. 


\section{DAFTAR PUSTAKA}

1. Suroso, D. Priyantoro, and Z. Kamal, Pengujian SIstem Mekanik Level Gauging. Seminar Nasional III SDM Teknologi Nuklir, 2007. Yogyakarta

2. Fendinugroho, Rancang Bangun Sistem Kendali Pemantauan Batas Permukaan (level Gauging) Dinamis Berbasis Mikrokontroler, in Seminar Nasional IV SDM Teknologi Nuklir2008, STTNBATAN: Yogyakarta.

3. Sunardi, J., S. Santoso, and F.N. Afzani, Rancang Bangun Sistem Monitor Level Gauging Statis Berbasis Mikrokontroler AT89S52. Seminar Nasional III SDM Teknologi Nuklir, 2007. Yogyakarta

4. Syarif, A., Komunikasi Data. Pusat Pengembangan Bahan Ajar Universitas Mercu Buana, 2008.

5. Khisan, I.K., Konsep Rancangan Pendeteksi Banjir Jarak Jauh Memanfaatkan Fasilitas Pesan Singkat (SMS). Makalah Seminar Kerja Praktek, 2011.

6. Setyanugroho, M.R., Akusisi Data Menggunakan Universal Serial Bus (USB). 2005.

7. Rahmalia, D.R., S.N.M.P. Simamora, and M. Dani, Sistem Pendeteksi Keamanan Ruang dengan Mikrokontroler ATMegal6 Berbasis Layanan SMS Gateway. Telkom Polytechnic, 2012.

8. Aryapandu, R.F., Komputerisasi Monitoring Radiasi Melalui Short Message Service (SMS), in TFN2013, Tugas Akhir STTN-BATAN: Yogyakarta.

9. Küstengemurmel, Z., GSM AT Command Set2001, Melbourn: UbiNetics 2001. Tersedia di http://www.zeeman.de/wpcontent/uploads/2007/09/ubinetics-atcommand-set.pdf,

10. Sukarman, Bahasa Pemrograman LabVIEW, 2006, STTN-BATAN: Yogyakarta.

11. Abimanyu, A., Rancang Bangun Sistem Pemantau Pengangkutan Zat Radioaktif menggunakan SMS Tersandi, in Teknik Elektro2014, Tesis Universitas Gadjah Mada: Yogyakarta. 